\title{
FAK Inhibitor GSK2256098
}

National Cancer Institute

\section{Source}

National Cancer Institute. FAK Inhibitor GSK2256098. NCI Thesaurus. Code C88346.

A focal adhesion kinase-1 (FAK) inhibitor with potential antiang iog enic and antineoplastic activities. FAK inhibitor GSK2256098 inhibits FAK, which may prevent the integ rinmediated activation of several downstream signal transduction pathways, including ERK, JNK/MAPK and PI3K/Akt, thereby inhibiting tumor cell migration, proliferation and survival, and tumor angiogenesis. The tyrosine kinase FAK is normally activated by binding to integ rins in the extracellular matrix (ECM) but may be upregulated and constitutively activated in various tumor cell types. 